\title{
Searching for New Measurement Solutions in the Area of Estimating Danger of Local Vibrations at Workplace
}

\author{
R. BARAŃSKI
}

Department of Mechanics and Vibroacoustics, AGH University of Science and Technology, Poland

There is a lot of controversy when we consider the most popular method of measuring local vibrations to estimate danger on hand tools operators. This is because of commonly used adapter that represents many faults, from which the most significant are: strong impact of grip and placing adapter between a hand and a tool handle. What we propose in this article is a measurement system including a band placed on a wrist. This solution highly eliminates defects mentioned above, but seems to be too trivial to maintain high quality of measuring process. The purpose of this article is to estimate the quality of this new solution in respect of some basic categories in which measurement errors occur.

PACS numbers: 07.10.- h, 46.40.-f

\section{Introduction}

Measuring the impact of local vibrations on a operator are still subject to scientific research. Some of differences between measurement methods are: way of placing sensor (different parts of hand [1], elbow [2]), sensor type (laser sensor [1, 2], acceleration sensor), sensor fastening (sticker reflecting laser beam $[1,2]$, band grip). Application of laser sensor usually brings advantages only in laboratory environment. When we apply it to real workplace conditions, some basic requirements cannot be met (foundation stability, lack of obstacles between sensor and hand, also impossibility of measuring a tool in move). This is a reason to propose a solution which makes use of popular acceleration sensor placed with a band.

\section{Research}

Our research has been conducted with application of vibration inductor with a handle (Fig. 1). A band with acceleration sensor has been placed on a wrist and also directly on an inductor (Fig. 2).

The research has been conducted under following conditions

- forcing signal - stationary with amplitude control (with vertical dominant amplitude near $100 \mathrm{~Hz}$ ),

- six channel signal registration with use of NI USB 9233 measurement cards, dedicated software based on LabVIEW 8.0 and two tri-axial sensors: PCB 356A16 (placed on a handle (N)) and PCB 356A22 (placed on a hand $(\mathrm{R})$ ),

- measurement time - $10 \mathrm{~s}$.

There has been conducted 15 measuring series, 15 to 20 repetition in each. In every repetition we have calculated acceleration vector for signals that have been registered on a hand $(\mathrm{R})$ and a tool $(\mathrm{N})$. Then root mean

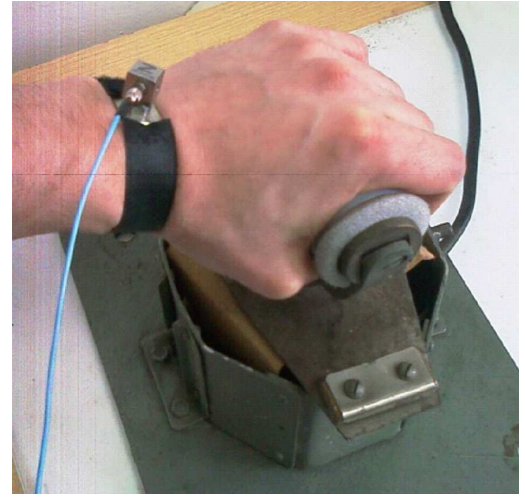

Fig. 1. Band on a wrist.

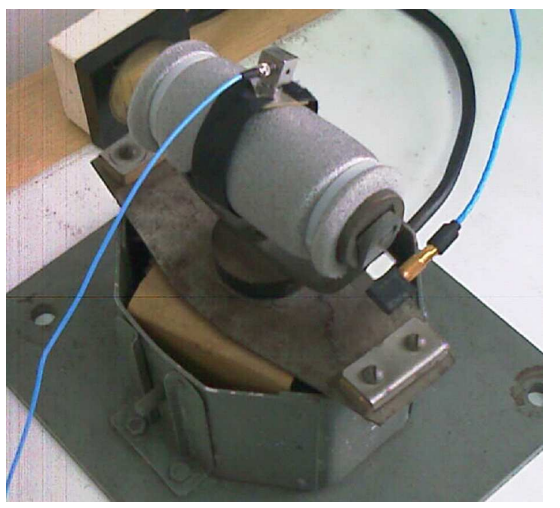

Fig. 2. Band on an inductor.

square $(r m s)$ has been determined. We have based on an assumption that forcing signal would be non-constant (which has been confirmed on further stage), so for calculations we have used signals which stood for difference between hand vector acceleration and tool vector acceleration.

All statistical analysis has been performed with Statistica 8.0 . 


\subsection{Bias}

Bias is a deviation between mean from a direct measurement and real value [3].

Taking under consideration that no counterpart for this type of measurement system is known, there was no possibility to test and verify this parameter.

\subsection{Repeatability}

Repeatability is a deviation of direct measurement made from one operator several times on the same element (when the same conditions preserved) [3].

Measurement has been conducted in three ways (a) a band with a sensor placed on a hand (each time after measurement a hand was taken off a handle and a band was removed) (Table Ia),

(b) a band with a sensor placed on a hand (each time after measurement a hand was taken off a handle but a band stayed in place) (Table Ib),

(c) a band with a sensor placed on an inductor's handle (each time after measurement a band was removed) (Table Ic).

TABLE I

Measurement of repeatability.

\begin{tabular}{|c|c|c|c|c|c|c|c|c|c|}
\hline & No. & $\begin{array}{l}\text { Mean } \\
{\left[\mathrm{m} / \mathrm{s}^{2}\right]}\end{array}$ & $\begin{array}{c}\text { Minimum } \\
{\left[\mathrm{m} / \mathrm{s}^{2}\right]}\end{array}$ & $\begin{array}{c}\text { Maximum } \\
{\left[\mathrm{m} / \mathrm{s}^{2}\right]}\end{array}$ & $\begin{array}{c}\text { Variance } \\
{\left[\mathrm{m} / \mathrm{s}^{2}\right]}\end{array}$ & $\begin{array}{c}\text { Standard } \\
\text { deviation } \\
{\left[\mathrm{m} / \mathrm{s}^{2}\right]}\end{array}$ & $\begin{array}{c}\text { Coeff. of } \\
\text { variation } \\
{[\%]}\end{array}$ & Skewness & Kurtosis \\
\hline \multicolumn{10}{|c|}{ (a) Band on hand (band removed) } \\
\hline series 4 & 20 & 3.734 & 3.341 & 4.080 & 0.051 & 0.227 & 6.066 & -0.222 & -0.842 \\
\hline \multicolumn{10}{|c|}{ (b) Band on hand (without band removed) } \\
\hline series 5 & 19 & 3.713 & 3.545 & 3.884 & 0.006 & 0.080 & 2.164 & 0.315 & 0.629 \\
\hline \multicolumn{10}{|c|}{ (c) Band on inductor's handle (band removed) } \\
\hline series 8 & 19 & 0.980 & 0.832 & 1.226 & 0.011 & 0.107 & 10.914 & 0.733 & -0.152 \\
\hline series 9 & 20 & 1.239 & 1.123 & 1.347 & 0.005 & 0.069 & 5.569 & 0.276 & -1.214 \\
\hline series 10 & 19 & 0.927 & 0.784 & 1.181 & 0.014 & 0.119 & 12.881 & 0.979 & 0.264 \\
\hline
\end{tabular}

\subsection{Reproducibility}

Reproducibility is a variation between average values from measurements of the same part with the same tool, conducted by different operators [3].

In our research there were three operators who done four series (in total) for one setting of vibration level on inductor. Each time after a measurement a band was placed on and taken off a handle. Taking under consideration significant discrepancy between the results when the band was on a hand (see Table Ib and c), we have decided to omit this aspect of uncertainty. As the setting of the vibrator remained unchanged, we have made an assumption that the results would have similar value. We have used variance analysis (ANOVA) to prove significant differences between means from our measurements. To do this, we had to make sure if the basic assumptions of the variance analysis had been met [4]:

(a) the variable is measurable (this condition has been met as we have used measurable acceleration values $\left.\mathrm{m} / \mathrm{s}^{2}\right)$,

(b) the dependent variable should be normally distributed within groups, (c) our distribution has homogeneity of variances.

Re: (b) we have used Lilliefors test and Shapiro-Wilks' $\mathrm{W}$ test. They have null hypothesis like in formula (2.1) and alternative hypothesis like in formula (2.2) (with statistical significance 0.05).

$$
\begin{aligned}
& H_{0}: N(\mu, \sigma)=N\left(\mu_{1}, \sigma_{1}\right) \\
& H_{0}: N(\mu, \sigma) \neq N\left(\mu_{1}, \sigma_{1}\right)
\end{aligned}
$$

\section{TABLE II}

Normal distribution test.

\begin{tabular}{c|cccc}
\hline \hline & No. & Lillief. $\mathrm{p}$ & $\mathrm{W}$ & $\mathrm{p}$ \\
\hline series 8 & 19 & $p>0.20$ & 0.940 & 0.26 \\
series 9 & 20 & $p>0.20$ & 0.922 & 0.11 \\
series 10 & 19 & $p>0.20$ & $\mathbf{0 . 8 9 6}$ & $\mathbf{0 . 0 4 1}$ \\
series 11 & 20 & $p<0.15$ & 0.914 & 0.076
\end{tabular}

If the value $p$ statistic is significant (less then 0.05), then the hypothesis that the respective distribution is normal should be rejected [4]. For the series 10 only Shapiro-Wilks' W test has significant $p$ statistic. 


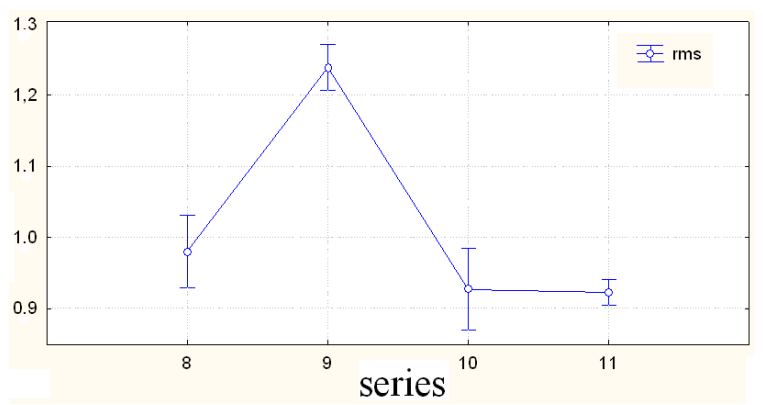

Fig. 3. Interaction diagram.

Re: (c) we have used Levene and Brown-Forsythe tests for homogeneity of variances with null hypothesis like formula (2.3) and alternative hypothesis like formula (2.4) (with statistical significance 0.05).

$$
\begin{aligned}
& H_{0}: \mu_{1}^{2}=\mu_{2}^{2}=\ldots=\mu^{2} \\
& H_{0}: \text { there is differences between any two means }
\end{aligned}
$$

The value $p$ statistic is significant (for Levene equal 0.0017 and for Brown-Forsythe equal 0.0087), so the hypothesis that the variances in the different groups are equal should be rejected. So we make some post hoc test like NIR, Scheffe's and Newman-Keuls test. All of this test shows significant difference between series 9 and others series (Fig. 3).

After elimination series 9, all tests have been repeated. In this time also the value $p$ statistic was significant (for Levene equal 0.0025 and for Brown-Forsythe equal 0.0087).

In spite of the value $p$ statistic was still significant (hypothesis that the variances in the different groups are equal should be rejected) we make analysis of variance (ANOVA). Result was not statistic significant (result equal 0.1218), so that there are no mean differences between groups or treatments in the population. Of course we must remember about not fulfillment all of assumption.

\subsection{Stability}

Stability is a total variation received during measuring certain value in a long time perspective [2].

We have conducted three measurements which duration was: $60 \mathrm{~s}, 425 \mathrm{~s}$ and $302 \mathrm{~s}$. Two analysis were made:

(a) analysis was obtained like a difference between $\mathrm{rms}$ value of handle vector acceleration and tool vector acceleration (Table III),

(b) we separated analyse handle vector acceleration and tool vector acceleration (Table IV).

TABLE III

Stability - difference.

\begin{tabular}{l|ccccccccc}
\hline \hline & No. & $\begin{array}{c}\text { Mean } \\
{\left[\mathrm{m} / \mathrm{s}^{2}\right]}\end{array}$ & $\begin{array}{c}\text { Minimum } \\
{\left[\mathrm{m} / \mathrm{s}^{2}\right]}\end{array}$ & $\begin{array}{c}\text { Maximum } \\
{\left[\mathrm{m} / \mathrm{s}^{2}\right]}\end{array}$ & $\begin{array}{c}\text { Variance } \\
{\left[\mathrm{m} / \mathrm{s}^{2}\right]}\end{array}$ & $\begin{array}{c}\text { Standard } \\
\text { deviation } \\
{\left[\mathrm{m} / \mathrm{s}^{2}\right]}\end{array}$ & $\begin{array}{c}\text { Coeff. of } \\
\text { variation } \\
{[\%]}\end{array}$ & Skewness & Kurtosis \\
\hline Series 2 measure 1 & 7 & 6.228 & 6.203 & 6.254 & 0.000401 & 0.020 & 0.322 & 0.312 & -1.867 \\
Series 16 measure 1 & 43 & 0.924 & 0.898 & 0.958 & 0.000352 & 0.019 & 2.031 & 0.455 & -1.247 \\
Series 16 measure 2 & 31 & 0.977 & 0.970 & 0.994 & 0.000042 & 0.006 & 0.661 & 1.509 & 1.225
\end{tabular}

TABLE IV

Stability — separate analysis.

\begin{tabular}{c|cccccccccc}
\hline \hline & No. & $\begin{array}{c}\text { Mean } \\
{\left[\mathrm{m} / \mathrm{s}^{2}\right]}\end{array}$ & $\begin{array}{c}\text { Minimum } \\
{\left[\mathrm{m} / \mathrm{s}^{2}\right]}\end{array}$ & $\begin{array}{c}\text { Maximum } \\
{\left[\mathrm{m} / \mathrm{s}^{2}\right]}\end{array}$ & $\begin{array}{c}\text { Variance } \\
{\left[\mathrm{m} / \mathrm{s}^{2}\right]}\end{array}$ & $\begin{array}{c}\text { Standard } \\
\text { deviation } \\
{\left[\mathrm{m} / \mathrm{s}^{2}\right]}\end{array}$ & $\begin{array}{c}\text { Coeff. of } \\
\text { variation } \\
{[\%]}\end{array}$ & Skewness & Kurtosis \\
\hline series 2 measure 1 N & 7 & 6.349 & 6.338 & 6.367 & 0.00014 & 0.012 & 0.189 & 0.987 & -1.001 \\
series 2 measure 1 R & 7 & 0.121 & 0.088 & 0.152 & 0.00068 & 0.026 & 21.546 & -0.039 & -1.996 \\
series 16 measure 1 N & 43 & 5.373 & 5.338 & 5.416 & 0.00051 & 0.023 & 0.421 & 0.404 & -0.918 \\
series 16 measure 1 R & 43 & 6.298 & 6.283 & 6.318 & 0.00008 & 0.009 & 0.143 & 0.718 & -0.053 \\
series 16 measure 2 N & 31 & 5.309 & 5.298 & 5.318 & 0.00003 & 0.005 & 0.094 & -0.030 & -0.319 \\
series 16 measure 2 R & 31 & 6.285 & 6.274 & 6.298 & 0.00004 & 0.006 & 0.100 & 0.240 & -0.742 \\
& & & & & & & & & &
\end{tabular}

\subsection{Linearity}

Linearity is variation of measurement accuracy in respect of measurement value [2].
We have conducted three measurement series (no. 13, 14, 15). Each of them consisted of 15 measurements in which value of vibration acceleration has been changed 
in linearity with preserving constant interval. Pearson correlation coefficient was obtained for each signal pair (tool $(\mathrm{N})$ and handle $(\mathrm{R}))($ Table $\mathrm{V})$.

TABLE V

Pearson correlation coefficient.

\begin{tabular}{l|ccc}
\hline \hline & $R(X, Y)$ & $r 2$ & $p$ \\
\hline series 13 N - series 13 R & 0.999836 & 0.999673 & 0.000000 \\
series 14 N - series 14 R & 0.999933 & 0.999865 & 0.000000 \\
series 15 N - series 15 R & 0.999966 & 0.999931 & 0.000000
\end{tabular}

\section{Conclusion}

Nowadays technical possibilities to build and implement new solution in industry or scientists research are very wide. With all this technical news very often we forgot about fundamental principle which is strongly statistical verification of our solution/invention. This article is a first step to implement a new measurement solution in the area of estimating danger of local vibrations at workplace. It could be also used by other to tests their own systems.

We try to verify all five categories of fundamental mistakes. However our system does not offer ability to mean accuracy. This property demands a very precise input control system like generator or possible to reproduce signal. Repeatability was computed by variation factor of the order of $6 \%$. Changing the band grip had a very strong impact on these categories. To compute reproducibility we have used variance analysis (ANOVA) and the result was not statistically significant (no mean differences between groups or treatments in the population).
But we have computed this in spite of some of assumption (distribution has homogeneity of variances) was rejected. Stability express in percentage variation coefficient for analysis obtained like a difference between $\mathrm{rms}$ value of handle vector acceleration and tool vector acceleration has value between $0.3 \%$ to $2 \%$. It's a satisfying result. But to reduce this spread we propose an improvement of input system in the future. Last category is linearity. Pearson correlation coefficient obtain near to 1 . On the basis of presented result we can say that our system is close to satisfying requirement. But to gain more stable results some elements require improvement in order to:

- measure of clamp effect on a hand,

- conduct additional tests to determine reproducibility,

- assign more time to learn how to wear a band on a hand (we think that different level of clamp effect resulted in lack of variance homogeneity),

- apply more stable input system.

\section{References}

[1] M.A. Książek, J. Tarnowski, Archives of Acoustic, Vol. 31, 3, 299 (2006) .

[2] P. Kowalski, Indicator of vibration transfer in hand - tool system, doctor's thesis, Centralny Instytut Ochrony Pracy, 2001.

[3] T. Graber, Measurement Systems Analysis, Wroclaw University of Technology, StatSoft Polska, 2002.

[4] A. Stanisz, Statistic course with STATISTCA PL based on medicine example, Vol. 1, StatSoft Sp. z o.o., Cracow 2006, p. 532. 